\title{
KONSEP ATTRIBUTE BASED ACCESS CONTROL (ABAC) PADA LEMARI PENYIMPANAN BUKTI DIGITAL (LPBD)
}

\author{
Moh. Fadly Panende ${ }^{1}$, Yudi Prayudi ${ }^{2}$, Imam Riadi ${ }^{3}$ \\ ${ }^{1,2}$ Program Studi Magister Teknik Informatika, Universitas Islam Indonesia \\ ${ }^{3}$ Program Studi Sistem Informasi, Universitas Ahmad Dahlan Yogyakarta \\ ${ }^{1}$ fadlypanende@gmail.com, ${ }^{2}$ prayudi@ uii.ac.id, ${ }^{3 i m a m . r i a d i @ i s . u a d . a c . i d ~}$
}

\begin{abstract}
ABSTRAK
Faktor penting dalam proses investigasi sebuah kasus cybercrime yaitu hal yang terkait dengan barang bukti yang ditemukan. Bukti elektronik maupun bukti digital yang ditemukan dalam sebuah kasus kejahatan harus tetap terjaga keasliannya. Sistem lemari penyimpanan bukti digital (LPBD) menjadi salah satu solusi untuk permasalahan manajemen bukti digital yang berdasar pada digital evidence cabinet (DEC), hanya saja sistem tersebut belum dilengkapi dengan model access control yang baik. Access control yang terapkan terhadap LPBD sebelumnya dibuat hanya dengan mekanisme otentikasi dan otorisasi username dan password saja, tidak adanya parameter lain yang lebih kompleks untuk mendukung sebuah request pada sistem LPBD. Tujuan dilakukannya penelitian ini yaitu membuat model attribute based access control (ABAC) dan melakukan pengujian terhadap access control yang dibuat. Berdasarkan hasil pengujian ABAC yang dilakukan menggunakan tools yang dibuat khusus untuk menguji ABAC pada LPBD, bahwa access control dapat berjalan dengan baik dan berfungsi sebagaimana mestinya. Perancangan ABAC LPBD ini juga diharapkan dapat menjadi solusi terhadap permasalahan yang ada pada access control LPBD sebelumnya. Pendekatan menggunakan metode $\mathrm{ABAC}$ ini disebabkan $\mathrm{ABAC}$ merupakan model access control yang lebih fleksibel dalam penerapan attribute terhadap user, dan hierarchy XACML yang dapat mendukung kebutuhan access control yang digunakan pada LPBD.
\end{abstract}

Kata Kunci: Access Control, ABAC, XACML, LPBD.DEC

\begin{abstract}
An important factor of the investigation process of a cybercrime case is related to the evidence found. Electronic evidence and digital evidence found in a criminal case must be kept authentic. The digital evidence storage cabinet (LPBD) system is one of the solutions to digital evidence management problems based on digital evidence cabinet (DEC), only that the system is not equipped with a good access control model. The access control applied to the previous LPBD was created only with athentication mechanism and authorization of username and password only, no other more complex parameters to support a request on the LPBD system. The purpose of this research is to create an attribute model based access control (ABAC) and to test the access control that is made. Based on $\mathrm{ABAC}$ test results conducted using tools specially designed to test ABAC on LPBD, that access control can run well and function. The design of $A B A C$ is also expected to be a solution to the problems that exist onthe LPBD access control before. The ABAC method approach is because ABAC is a more flexible access control model in the application of attribute to user. XACML hierarchy can support access control requirement used in LPBD.
\end{abstract}

Keywords: Access Controls, ABAC, XACML, LPBD, DEC.

DOI: $10.15408 /$ jti.v11i1.7220 


\section{PENDAhuluaN}

Perkembangan teknologi informasi saat ini tidak hanya memberikan dampak positif bagi penggunanya, melainkan juga dampak negatif, Berdasarkan data dari Polda Metro Jaya terdapat 1.207 kasus cybercrime pada tahun 2016 dengan 699 kasus yang terselesaikan. Data ini menjukan bahwa cybercrime sudah menjadi permasalahan yang serius di era digital ini.

Salah satu faktor penting dalam proses investigasi sebuah kasus cybercrime yaitu hal yang terkait dengan barang bukti [1], dalam hal ini yang dimaksud yaitu barang bukti elektronik dan barang bukti digital. Bukti elektronik adalah barang bukti yang bersifat fisik dan dapat dikenali secara visual seperti (komputer, handphone, camera, $\mathrm{CD}$, hardisk, dan lain-lain) sedangkan bukti digital adalah barang bukti yang berisi informasi-informasi digital hasil ekstaksi dari bukti elektronik. Bukti digital merupakan alat bukti yang sah dipengadilan, sebagaimana yang dijelaskan oleh [2] dalam penelitiannya bahwa informasiinformasi digital yang tersimpan didalam perangkat elektronik dapat digunakan sebagai alat bukti yang sah sebagaimana diatur dalam UU ITE Nomor 11 Tahun 2008 Pasal 5 Ayat 1 yang berbunyi "Informasi Elektronik dan/atau Dokumen Elektronik dan/atau hasil cetaknya merupakan alat bukti hukum yang sah". Penanganan bukti digital dapat menjadi bukti adanya tekad bahwa kejahatan telah dilakukan atau mungkin memberikan hubungan antara kejahatan dan korban atau kejahatan dan pelakunya [3]. Dalam proses menyelidiki kasus kejahatan digital, bukti digital diperlukan untuk menyelesaikan kasus-kasus yang ada [4]. Untuk itu bukti digital yang ditemukan dalam sebuah kasus kejahatan harus tetap terjaga keasliannya, agar dapat dipertanggung jawabkan dipengadilan.

Sejumlah penelitian yang telah dilakukan sebagai upaya untuk mengimplementasikan konsep penanganan bukti digital. Namun demikian mengingat karakteristik barang bukti yang terus berkembang dan semakin kompleks maka muncullah salah satu solusi yang ditawarkan [5] yaitu model digital evidence cabinets sebagai pendekatan baru yang diimplementasikan dalam penanganan bukti digital dan chain of custody. Solusi ini diorentasikan untuk memberikan penyelesaian masalah penyimpanan bukti digital. Model tersebut telah diimplementasikan [6] dalam bentuk sistem Lemari Penyimpanan Bukti Digital (LPBD). Namun sayangnya sistem tersebut masih dalam tahap awal dan belum dilengkapi dengan rancangan akses kontrol yang baik.

Lemari penyimpanan bukti digital seharusnya dibuat tidak hanya berdasar pada permasalahan-permasalahan tentang manajemen bukti digital saja, akan tetapi komponen-komponen penting lainnya dalam lemari penyimpanan bukti digital itu sendiri yaitu pengaturan aksesnya, sehingga skema atau desain akses kontrol policy terhadap Lemari Penyimpanan Bukti Digital ini menjadi sangat penting.

Beberapa kemungkinan solusi model akses kontrol yang sudah pernah ada sebelumnya seperti discretionary access control (DAC), mandatory access control (MAC), access control list (ACL), serta rule based access control (RBAC) dan lain-lain, untuk mengatasi permasalahan akses kontrol pada lemari penyimpanan bukti digital ini digunakan model Attribute Based Access Control (ABAC) sebagai generasi baru dari generasi sebelumnya, karena konsep tersebut memiliki fleksibilitas terhadap desain akses kontrol dan juga merupakan pengembangan dari akses kontrol yang pernah ada sebelumnya.

Access Control terhadap LPBD tidak cukup hanya ditangani oleh mekanisme otentifikasi dan otorisasi user saja. Otentifikasi, otorisasi dan access control memiliki fungsi dan tujuan yang berbeda walaupun pada implementasinya seolah-olah terlihat sebuah proses tunggal. Menurut [7] otentifikasi fokusnya pada verifikasi terhadap klaim identitas user, otorisasi fokusnya pada pemberian hak akses terhadap resource, sementara access control fokusnya pada proteksi keamanan yang diterapkan. Akses kontrol melindungi sistem dan sumber daya dari akses yang tidak berhak dan menentukan tingkat otorisasi setelah prosedur otentifikasi berhasil dilengkapi [8].

Mengingat belum adanya skema rancangan model akses kontrol yang baik pada LPBD ini, maka perlu dilakukan perancangan model akses kontrol policy menggunakan pendekatan attribute based access control (ABAC) yang mendukung kebutuhan Lemari Penyimpanan Bukti Digital (LPBD) itu sendiri. Hasil akhir dari penelitian ini adalah 
terciptanya model attribute based access control policy untuk memberikan hak akses bagi pengguna yang diberi kewenangan menangani bukti digital yang ada pada LPBD

\section{TINJAUAN PUSTAKA}

dari bagian-bagian yang berhubungan langsung dengan bukti digital, penyimpanan informasi metadata bukti digital maupun kontrol akses dan kemananan terhadap digital CoC [6]. Konsep ini diperkenalkan oleh [9] dalam penelitiannya yang berjudul Digital Evidence Cabinets: A Proposed Frameworks for Handling Digital Chain of Custody. Dalam penelitiannya disebutkan bahwa LPBD merupakan sistem yang dibuat untuk penanganan $\mathrm{CoC}$ dari setiap bukti digital yang telah diperoleh. Konsep ini dibangun atas 3 pendekatan, yaitu: Digital Evidence Management Frameworks, kantong bukti digital dan keamanan. Penelitian yang dilakukan oleh [10] dikatakan bahwa Peran artefak (misalnya metadata) dalam analisis forensik dan (prospektif) adalah hilangnya artefak ini saat data dikumpulkan dari lingkungan komputasi awan. Jika metadata (misal: tanggal pembuatan/modifikasi dari sebuah file, dan mencatat kepemilikan pengguna) yang hilang selama proses pengumpulan. Ini mempengaruhi kemampuan peneliti untuk melakukan penyelidikan forensik terhadap standar yang disyaratkan oleh pengadilan. Penelitian lain yang dilakukan oleh [11] menawarkan metode solusi perlindungan bagi pengguna dalam aplikasi browser yang akan difilter, menonaktifkan plugin, memberi tahu, memblokir, dan mengurangi serangan Cross Site Scripting.

ABAC adalah sebuah metode acces control dimana subject hanya akan dapat melakukan request untuk menjalankan sebuah operasi terhadap object didasarkan pada attribute yang disematkan pada subjek, objek, kondisi lingkungan serta kumpulan policy yang termasuk dalam attribute dan kondisinya. Pada sistem ABAC, elemen otorisasi didefinisikan dalam terminologi attribute. Attribute itu sendiri adalah karakteristik dari entitas yang didefinisikan sebelumnya oleh pihak yang memiliki wewenang untuk itu. Menurut [12] ide dasar utama dari ABAC adalah tidak memberikan permission sebagai ouput dari hubungan langsung antara subjek dan objek namun mendasari pemberian permission tersebut melalui attribute dari keduanya.

Menurut [13], terdapat 4 aspek attribute dalam ABAC, yaitu:

1.

ubject adalah pengguna manusia ataupun non manusia misalnya (device ataupun komponen software) yang meminta request access. Contoh dari attribute untuk subject adalah: nama, tanggal lahir, alamat rumah, pekerjaan. Sementara itu request access dapat menggunakan attribute individual dari subject atau kombinasinya untuk menunjukkan identitas yang unik.

2.

esource adalah sesuatu target yang dilindungi seperti halnya device, files, record, table, proses, program, jaringan.

3.

ctions adalah eksekusi dari suatu fungsi pada saat melakukan request dari sebuah subject terhadap resource. Sebagai contoh, actions terhadap file data akan melibatkan creation, modification dan deletion.

4.

nvironment attribute adalah karakteristik dari operational ataupun situational seperti misalnya current time, current temperature, IP address.

Penelitian yang dilakukan oleh [14] yang menyajikan permasalahan sistem kontrol akses lintas domain $\mathrm{ABAC}$ bersama dengan domain keamanan sebagai attribute dengan subjek, objek, otoritas, attribute lingkungan sebagai dasar akses untuk akses pengambilan keputusan. Penelitian selanjutnya yang dilakukan oleh [15] penelitian ini berfokus pada permintaan penulisan ulang yang menerima tanggapan yang tidak sesuai dengan mengurangi sumber daya yang diperlukan untuk diselaraskan dengan kebijakan sistem, mereka membuat model baru memanfaatkan framework XACML 3.0 untuk mengetahui kebijakan yang paling sesuai untuk setiap permintaan masukan dalam empat aspek, termasuk tindakan subject, lingkungan dan sumberdaya untuk petmintaan menulis ulang.

XACML (eXtensible Access Control Markup Language) adalah standar dari OASIS untuk menspesifikasikan ABAC policy menggunakan format XML. Terdapat 4 
attribute predefined yaitu: subject, resource, action dan environment. Namun type user attribute dapat juga diterapkan untuk aplikasi tertentu. XACML mendukung berbagai type data, type nama serta path expression untuk attribute misalnya: string, integer, internetbased names, regular expression dan XPATH. Dalam hal penggunaan attribute, type data lebih utama dispesifikasikan dibandingkan dengan domain [16].

\section{METODOLOGI}

Alur penelitian dengan menjabarkan setiap proses yang dibuat secara sistematis. Hal ini agar permasalahan yang dihadapi dapat terselesaikan, hasil dan kesulitan-kesulitan yang ditemukan saat proses penelitian sedang berlangsung dapat dianalisis. Alur penelitian dapat dilihat pada Gambar 1.

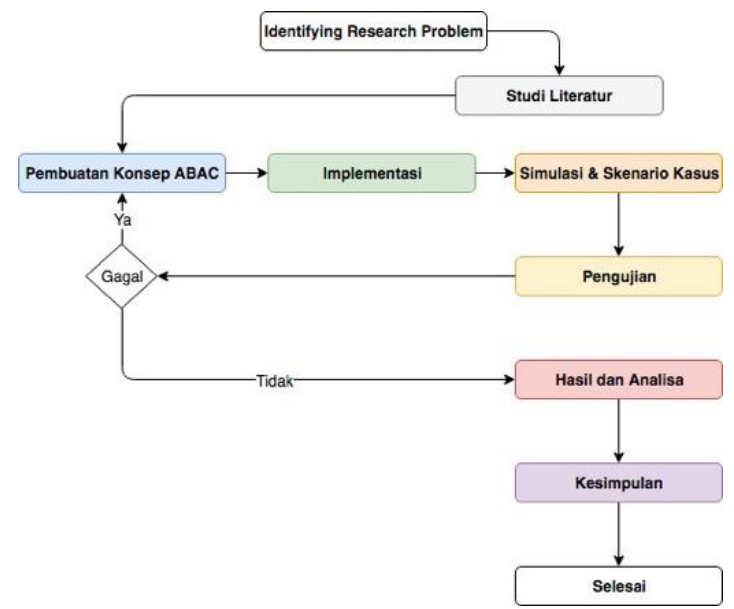

Gambar 1. Alur penelitian

Gambar 1 menjelaskan bahwa alur penelitian yang digunakan dalam penelitian ini adalah, diawali dengan identifying research problem, dilanjutkan dengan studi literatur untuk mendapatkan referensi-referensi tentang penelitian sebelumnya, selanjutnya membuat konsep ABAC, implementasi, melakukan simulasi dan skenario kasus, melakukan pengujian $\mathrm{ABAC}$, jika pengujian gagal maka akan kembali ke perancangan konsep ABAC jika pengujian berhasil maka akan dilanjutkan pada hasil dan analisa, dan yang terakhir menyimpulkan hasil penelitian.

\section{GAMBARAN RANCANGAN ACCESS CONTROL LPBD}

Perancangan konsep model attribute based access control (ABAC) ini dimulai dengan gambaran umum cara kerja akses kontrol yang dibangun. Rancangan ABAC pada LPBD ini dianalogikan sebagai sebuah proses login yang dimana proses otentifikasi dan autorisasinya dilakukan melalui rule policy yang disematkan pada setiap user yang memiliki hak akses pada LPBD sebagai subject dan resource pada aplikasi sebagai object. Rancangan access control ini dibuat agar dapat mengidentifikasi setiap user yang mengakses aplikasi dikarenakan LPBD merupakan sebuah aplikasi yang bersentuhan langsung dengan metadata bukti digital yang harus tetap terjaga keaslianya agar dapat dipertanggungjawabkan di pengadilan [1]. Gambar 3 menjelaskan tentang umum ABAC pada LPBD.

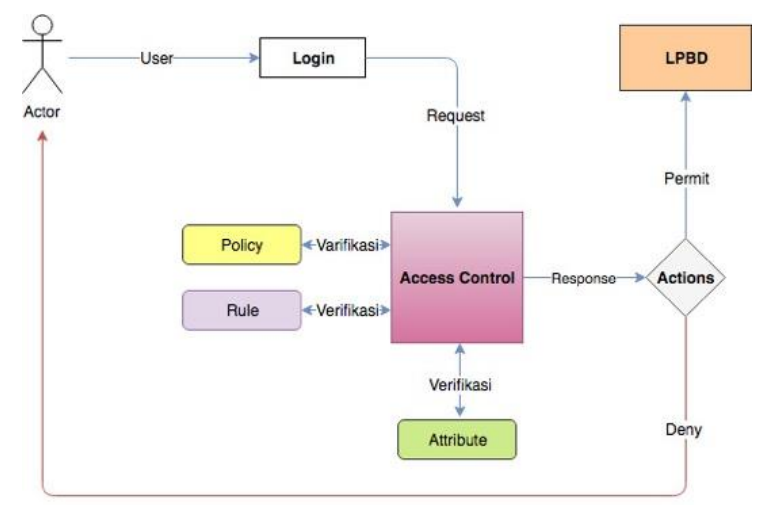

Gambar 2. Gambaran umum ABAC LPBD

XACML LPBD data flow model merupakan gambaran logika yang terlibat dalam melakukan pemrosesan terhadap sebuah permintaan akses. Gambar 3 menjelaskan model XACML data flow LPBD.

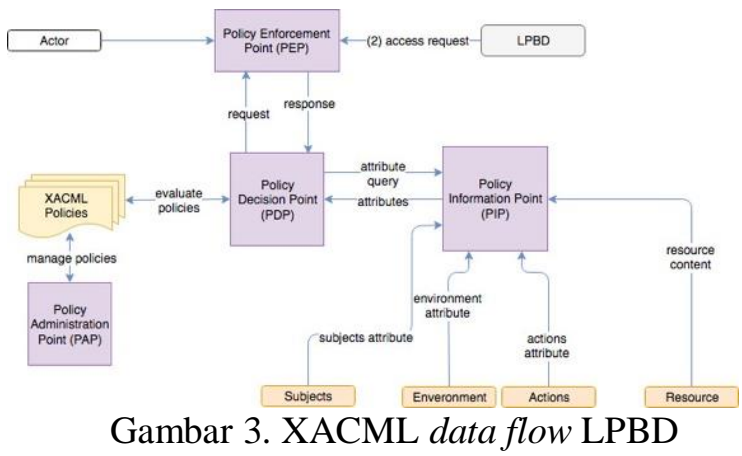

Gambar 3 menjelaskan bahwa policy enfronce point (PEP) sebagai pelaksana awal ketika dilakukannya permintaan akses, selanjutnya yang memberikan request terhadap policy decision point (PDP) yang bertugas sebagai yang memutuskan permintaan, dan 
policy information point (PIP) yang berperan sebagai yang menampung 4 jenis attribute yaitu subject, resource, actions, dan environment. Policy decision point (PDP) dalam hal ini berfungsi untuk mengevaluasi XACML policies yang berada pada policy administration point (PAP) yang berfungsi sebagai yang mengolah XACML policy tersebut.

\section{HASIL DAN PEMBAHASAN}

Policy statement merupakan tahapan awal pada perancangan access control LPBD ini, yaitu berupa usulan attribute yang akan digunakan dan telah disesuaikan dengan kebutuhan-kebutuhan yang ada pada istem LPBD dan kebutuhan-kebutuhan yang ada pada ABAC. Tabel 1 merupakan penjelasan tentang usulan attribute pada sistem LPBD.

Tabel 1. Usulan attribute

\begin{tabular}{|c|c|c|c|}
\hline Subject & Resource & Actions & Environment \\
\hline \multirow{5}{*}{$\begin{array}{l}\text { First } \\
\text { Responder }\end{array}$} & $\begin{array}{l}\text { Upload } \\
\text { Digital } \\
\text { Evidence }\end{array}$ & Upload & \multirow{5}{*}{$\begin{array}{l}\text { Ip Address } \\
\text { Mac Addres } \\
\text { Time Akses }\end{array}$} \\
\hline & $\begin{array}{l}\text { Create } \\
\text { Cabinet }\end{array}$ & Create & \\
\hline & Create Rack & Create & \\
\hline & Create Bag & Create & \\
\hline & $\begin{array}{l}\text { Input Data } \\
\text { Case Coc }\end{array}$ & Input & \\
\hline \multirow{2}{*}{ Investigator } & $\begin{array}{l}\text { Download } \\
\text { Digital } \\
\text { Evidence }\end{array}$ & Download & \multirow{2}{*}{$\begin{array}{l}\text { Ip Address } \\
\text { Mac Addres } \\
\text { Time Akses }\end{array}$} \\
\hline & $\begin{array}{l}\text { Complete } \\
\text { The Data } \\
\text { Coc }\end{array}$ & $\begin{array}{l}\text { Complete } \\
\text { Data }\end{array}$ & \\
\hline \multirow{7}{*}{ Officer } & $\begin{array}{l}\text { Delete } \\
\text { Digital } \\
\text { Evidence }\end{array}$ & Delete & \multirow{7}{*}{$\begin{array}{l}\text { Ip Address } \\
\text { Mac Addres } \\
\text { Time Akses }\end{array}$} \\
\hline & $\begin{array}{l}\text { Change } \\
\text { Password } \\
\text { User }\end{array}$ & $\begin{array}{l}\text { Change } \\
\text { Password }\end{array}$ & \\
\hline & $\begin{array}{l}\text { Validate } \\
\text { Digital } \\
\text { Evidence }\end{array}$ & Validate & \\
\hline & $\begin{array}{l}\text { Validate } \\
\text { Case Status }\end{array}$ & Validate & \\
\hline & $\begin{array}{l}\text { Download } \\
\text { Form Coc }\end{array}$ & Download & \\
\hline & $\begin{array}{l}\text { Change Code } \\
\text { Signature }\end{array}$ & $\begin{array}{l}\text { Change } \\
\text { Code }\end{array}$ & \\
\hline & $\begin{array}{l}\text { Validate } \\
\text { Data Coc }\end{array}$ & Validate & \\
\hline Layer & $\begin{array}{l}\text { Download } \\
\text { Form Coc }\end{array}$ & Download & $\begin{array}{l}\text { Ip Address } \\
\text { Mac Addres } \\
\text { Time Akses }\end{array}$ \\
\hline
\end{tabular}

Tabel 1 menjelaskan bahwa dalam sebuah policy statement yang dibangun pada sistem LPBD berisi empat buah subject yang merupakan jabatan user yaitu first responder, investigator, officer, dan lawyer, lima belas buah resource sebagai object yaitu, upload digital, sembilan buah actions, dan tiga buah evinronment yang merupakan kondisi lingkungan saat request dilakukan, subject yang pertama yaitu first responder mempunyai hak melakukan operasi pada resource: upload digital evidence, create cabinet, create rack, create bag, dan input data case coc, serta actions: upload, create, dan input. Environment yang digunakan yaitu ip address, mac address, dan time access. Subject yang kedua yaitu investigator memeiliki dua hak akses pada resource yaitu download digital evidence dan complete the data coc, actions: download dan complete data serta environment: ip address, mac address, dan time access. Subject yang ketiga yaitu officer memiliki hak akses pada resource: delete digital evidence, change password user, validate digital evidence, validate cese status, download form coc, change code signature, dan validate data coc. Actions yang dimiliki yaitu delete, change password, validate, download, dan change code. Environment: ip address, mac address, dan time access. Subject yang keempat yaitu lawyer hanya memiliki satu hak akses resource yaitu download form coc, dan action: download, serta inveronment: ip address, mac address dan time access. Policy statement ini merupakan komponenkomponen yang akan dimasukan kedalam rules dan akan menjadi ekspresi logika untuk memenuhi setiap request yang dilakukan oleh user. Sebagaimana yang terlihat pada Gambar 4.

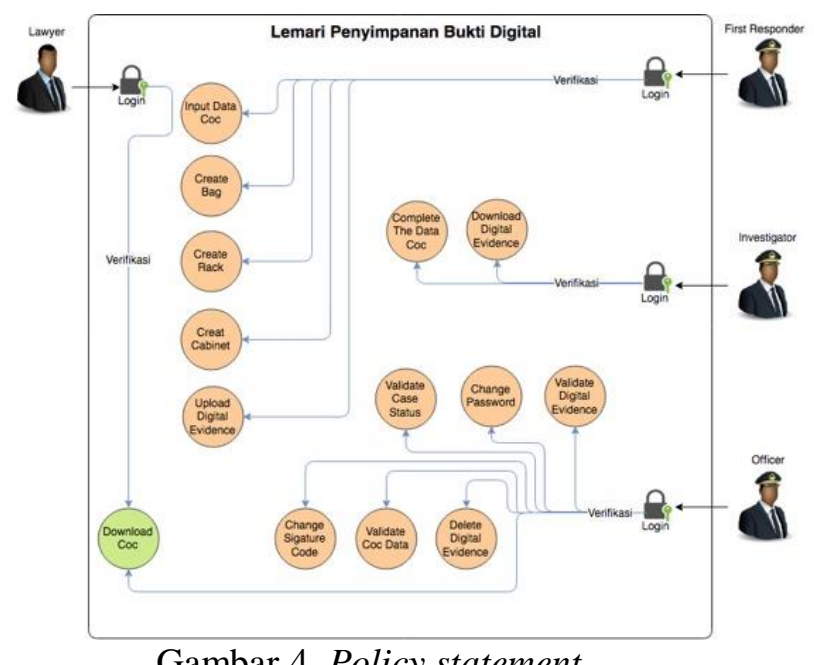

Gambar 4. Policy statement

Struktur XACML policy yang dibangun berdasarkan kebutuhan-kebutuhan yang ada 
pada LPBD, serta dirancang menggunakan tools khusus untuk membuat sebuah XACML policy. Tools yang digunakan yaitu UMUXACML-Editor Versi 1.3.2 Proses pembuatan policy terbagi atas dua bagian yaitu menentukan satu policy target serta satu rule hal ini bertujuan agar dapat dengan mudah menempatkan attribute yang akan disematkan pada setiap elemen yang ada seperti subject, resource, actions, dan environment. Berikut adalah sample pembuatan struktur XACML policy LPBD. Gambar 5 menjelaskan tentang XACML policy yang dibuat menggunakan UMU XACML Editor.

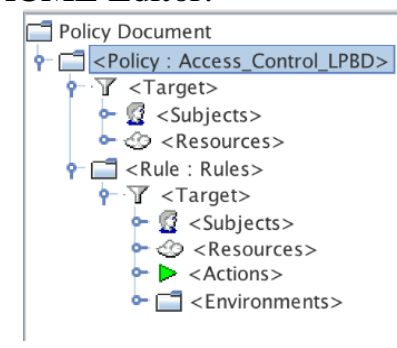

Gambar 5. XACML policy UMU XACML editor

Gambar 5 menjelaskan bahwa langkah pertama yang dilakukan yaitu menentukan nilai pada policy target yang juga merupakan root element pada rancangan XACML policy ini, policyid diberinama access control policy $\angle P B D$ dan rule combining algorithm diisi dengan nilai first applicable hal ini bertujuan karena policy LPBD mempunyai request lebih dari 1 rule. Target policy berisi 4 subject yang artinya bahwa ada 4 user yang diizinkan melakukan pada LPBD yaitu first responder, investigator, officer, dan lawyer. Selain subject, target policy juga berisi 15 resource yang artinya merupakan jumlah keseluruhan resource yang ada pada LPBD.

Setelah menjelaskan bagaimana perancangan dilakukan maka langkah selanjutnya yaitu menjelaskan sample output dari rancangan XACML policy yang telah dibuat. Gambar 6 menjelaskan tentang sample output attribute subject.

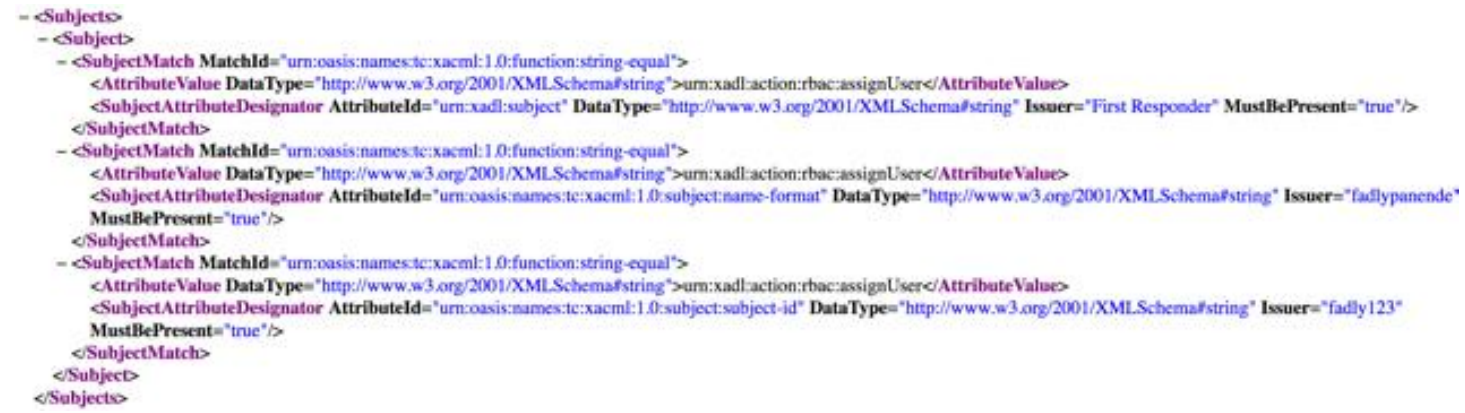

Gambar 6. Sample output subject

Gambar 6 menjelaskan bahwa sample attribute subject yang ditampilkan adalah output subject dari user first responder yang artinya sample subject ini berisi attribute jabatan yang diisi dengan nama first responder, username diisi dengan fadlypanende dan subjectId diisi dengan fadly123 yang artinya bahwa seseorang yang melakukan akses pada LPBD yaitu user yang menjabat sebagai first responder bernama fadlypanende dan password fadly 123 .

Gambar 7 menjelaskan output sample atttribute resource. 


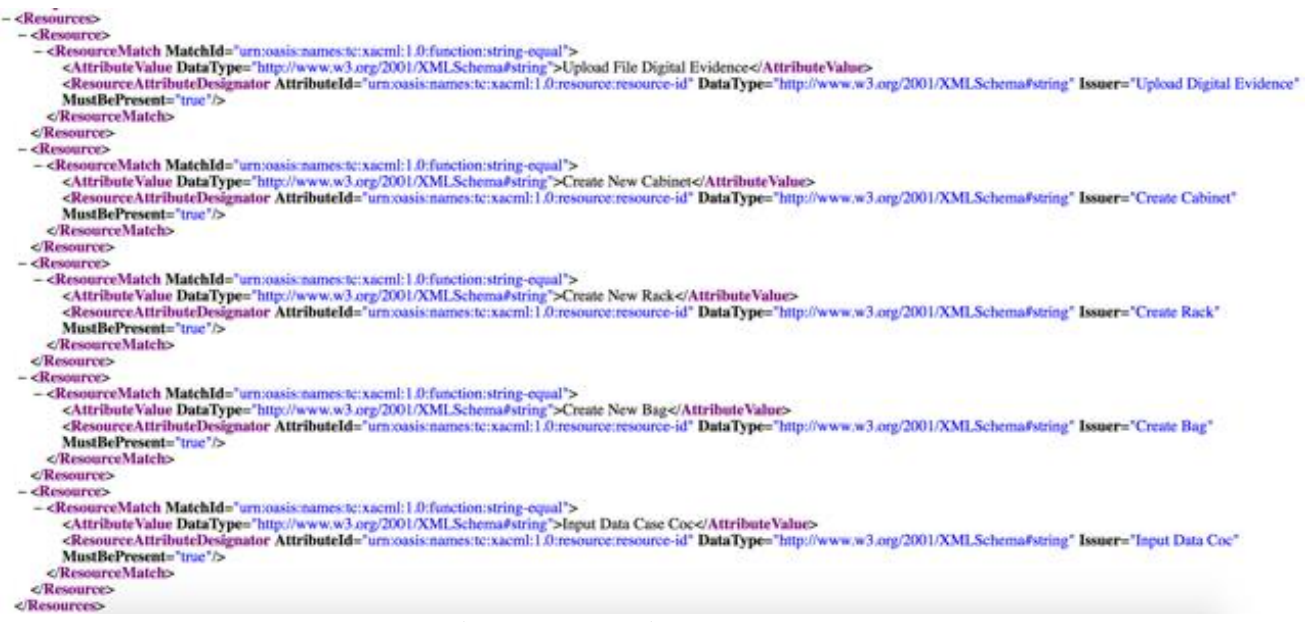

Gambar 7. Sample output resource

Gambar 7 menjelaskan bahwa sample attribute resource yang ditampilkan pada Gambar 7 merupakan sample attribute resource yang diberikan pada user first responder yang artinya bahwa seseorang yang memiliki wewenang sebagai first responder dapat diberikan izin melakukan akses pada
LPBD atas dasar identitas resource yang diberikan berupa upload file digital evidence, create new cabinet, create new rack, create new bag, dan input data coc.

Tahapan selanjutnya menjelaskan sample attribute output actions sebagaimana yang terlihat pada Gambar 8.

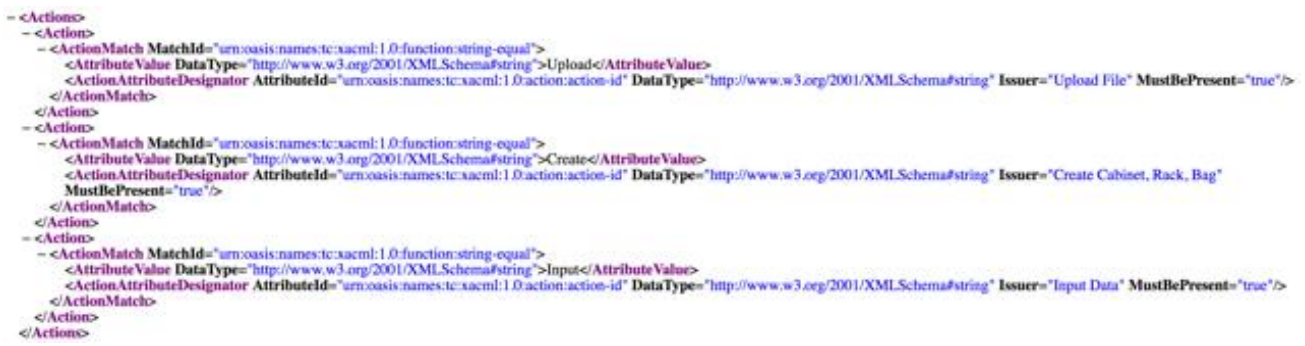

Gambar 8. Sample output actions

Gambar 8 menjelaskan bahwa output sample attribute actions yang ditampilkan pada Gambar 8 merupakan sample attribute actions yang diberikan pada user first responder yang artinya bahwa seseorang yang memiliki kewenangan sebagai first responder dapat diberikan izin melakukan akses pada
LPBD atas dasar identitas actions yang diberikan berupa upload file, create cabinet, rack, bag dan input data.

Tahapan akhir dari penjelasan sample output XACML policy ini yaitu sample output attribute environment sebagaimana yang terlihat pada Gambar 9.

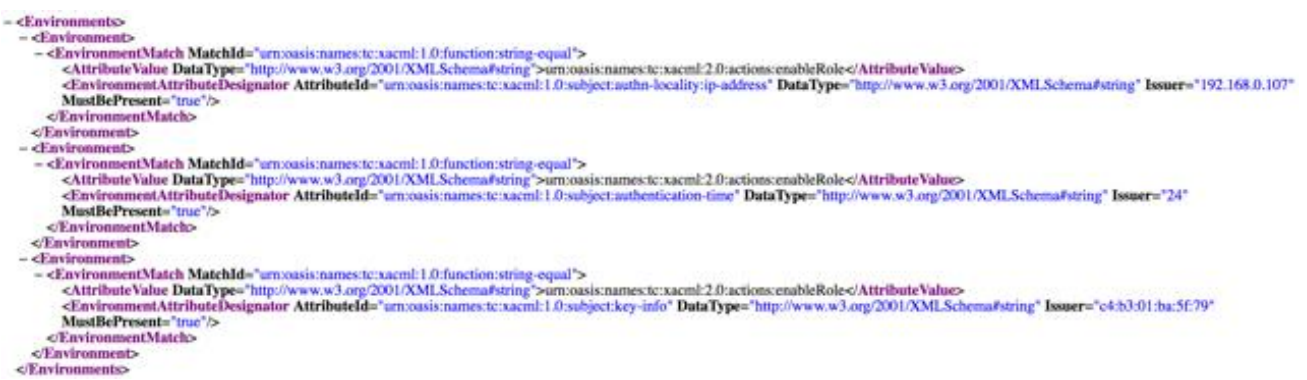

Gambar 9. Sample output environment

Gambar 9 menjelaskan bahwa sample output attribute environment yang ditampilkan pada Gambar 9 merupakan sample attribute environment yang diberikan pada user first 
responder yang artinya bahwa seseorang yang memiliki kewenangan sebagai first responder dapat melakukan akses pada LPBD atas dasar identitas attribute environment yang diberikan berupa ip address: 192.168.0.107, time access: 24 atau tidak ada batasan waktu akses, dan mac address: c4:b3:01:ba:5f:79.

Aktivitas pengujian access control LPBD dilakukan menggunakan sebuah tools yang dibuat khusus untuk menguji kinerja access control yang dibuat pada LPBD. Pengujian yang ditampilkan menggunakan tools testing access control ini menggunakan 1 sample kondisi permit dan 1 sample kondisi deny serta user first responder, karena pada dasarnya hanya ada dua kemungkinan decision ketika subject melakukan request terhadap object yaitu kondisi permit dan deny [17].

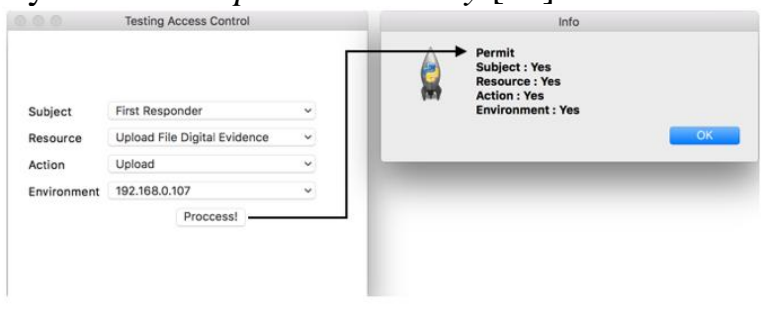

Gambar 10. Pengujian kondisi permit

Gambar 10 menjelaskan bahwa pengujian kodisi permit terjadi ketika melakukan "klik" tombol process maka kondisi yang dihasilkan yaitu permit disebabkan semua attribute yang dimasukan benar, seperti yang terlihat pada halaman info permit subject: yes, resource: yes, actions: yes dan environment:yes. Attribute yang dimasukan yaitu subject: first responder, resource: upload file digital evidence, actions: upload, dan environment: ip address 192.168.0.107.

Selanjutnya melakukan pengujian kondisi deny. Gambar 11 menjelaskan kondisi deny.

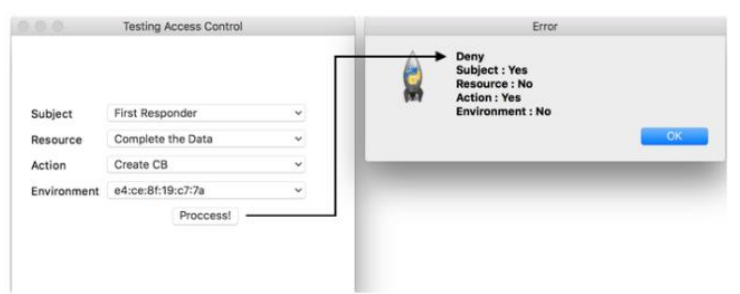

Gambar 11. Pengujian kondisi deny

Gambar 11 menjelaskan bahwa sample pengujian kondisi deny menggunakan user first responder, ketika melakukan "klik" tombol process kondisi yang dihasilkan adalah deny sebagaimana yang terlihat pada halaman info deny bahwa subject: yes, resource: no, actions: yes, environment: no, terdapat 2 kesalahan yaitu pertama terdapat pada masukan resource yang diisi dengan complete the data dan kesalahan kedua terdapat pada masukan environment yang diisi dengan e4:ce:8f:19:c7:7a hal ini disebabkan bahwa attribute resource dan environment yang dimasukan bukan merupakan attribute user first responder melainkan attribute user investigator.

Aktivitas pengujian access control yang dilakukan pada LPBD ini merupakan pengujian fungsionalitas yang meliputi kemampuan menerapkan rule policy untuk proses login pada sistem LPBD.

Tabel 2 berikut merupakan penjelasan mengenai hasil pengujian 1 sample kondisi permit dan 1 sample kondisi deny.

Tabel 2 Hasil pengujian kondisi permit \& deny

\begin{tabular}{|c|c|c|c|c|}
\hline Subject & Resource & Actions & Environment & Outpu \\
\hline $\begin{array}{l}\text { First } \\
\text { Responder }\end{array}$ & $\begin{array}{l}\text { Upload } \\
\text { File } \\
\text { Digital } \\
\text { Evidence }\end{array}$ & Upload & $\begin{array}{l}\text { Ip Address: } \\
\text { 192.168.0.107 }\end{array}$ & Permit \\
\hline $\begin{array}{l}\text { First } \\
\text { Responder }\end{array}$ & $\begin{array}{l}\text { Complete } \\
\text { The Data }\end{array}$ & $\begin{array}{l}\text { Create } \\
C B\end{array}$ & $\begin{array}{l}\text { Mac Address: } \\
\text { e4:ce:8f:19:c7:7a }\end{array}$ & Deny \\
\hline
\end{tabular}

Tabel 2 menjelaskan bahwa pengujian kondisi permit dan deny mendapatkan satu kondisi permit yang disebabkan keseluruhan attribute yang dimasukkan merupakan attribute yang telah disematkan pada user yaitu subject first responder, resource: upload bukti digital, actions: upload dan environment: address 192.168.0.107. Sementara kondisi deny disebabkan karena ada dua kesalahan masukan attribute yaitu attribute resource: complete the data dan attribute environment: mac address e4:ce:8f:19:c7:7a yang bukan merupakan attribute yang ada pada user first responder.

Pengujian access control LPBD sebagaimana yang terlilhat pada Tabel 3 merupakan hasil pengujian access control menggunakan keselurahan attribute pada 4 user yaitu first responder, investigator, officer, dan lawyer yang divisualisasikan dalam bentuk tabel berisi hasil pengujian yang dilakukan menggunakan tools testing access control LPBD. Pengujian ini dilakukan agar dapat mengetahui bagaimana hasil kinerja access control secara keseluruhan dalam penerapan attribute subject, resource, actions, dan environment yang disematkan pada user. Tabel 
3 menjelaskan tentang hasil pengujian secara keseluruhan attribute.

Tabel 3. Hasil Pengujian ABAC LPBD

\begin{tabular}{|c|c|c|c|c|}
\hline Subject & Resource & Actions & Environment & Output \\
\hline \multirow{6}{*}{$\begin{array}{l}\text { First } \\
\text { Responder }\end{array}$} & Upload & & \multirow{6}{*}{$\begin{array}{l}\text { IP Address: } \\
\text { 192.168.0.107 } \\
\text { Mac Address: } \\
\text { c4:b3:01:ba:5f:79 } \\
\text { Time Access: } \\
24\end{array}$} & \\
\hline & $\begin{array}{l}\text { Digital } \\
\text { Evidence }\end{array}$ & Upload & & Permit \\
\hline & $\begin{array}{l}\text { Create } \\
\text { Cabinte }\end{array}$ & Create & & Permit \\
\hline & $\begin{array}{l}\text { Create } \\
\text { Rack }\end{array}$ & Create & & Permit \\
\hline & $\begin{array}{l}\text { Create } \\
\text { Bag }\end{array}$ & Create & & Permit \\
\hline & $\begin{array}{l}\text { Input Data } \\
\text { Case COC }\end{array}$ & Input & & Permit \\
\hline \multirow{2}{*}{ Investigator } & $\begin{array}{l}\text { Download } \\
\text { Digital } \\
\text { Evidence }\end{array}$ & Download & \multirow{2}{*}{$\begin{array}{l}\text { IP Address: } \\
\text { 192.168.0.108 } \\
\text { Mac Address: } \\
\text { e4:ce:8f:19:c7:7a } \\
\text { Time Access: } \\
\mathbf{2 4}\end{array}$} & Permit \\
\hline & $\begin{array}{l}\text { Complete } \\
\text { Digital } \\
\text { Evidence }\end{array}$ & Complete & & Permit \\
\hline \multirow{7}{*}{ Officer } & $\begin{array}{l}\text { Delete } \\
\text { Digital } \\
\text { Evidence }\end{array}$ & Delete & \multirow{7}{*}{$\begin{array}{l}\text { IP Address: } \\
\text { 192.168.1.1 } \\
\text { Mac Address: } \\
\text { Fe80::4c2c:f62a: } \\
\text { de:a57c\%11 }\end{array}$} & Permit \\
\hline & $\begin{array}{l}\text { Change } \\
\text { Password }\end{array}$ & Change & & Permit \\
\hline & $\begin{array}{l}\text { Validate } \\
\text { Digital } \\
\text { Evidence }\end{array}$ & Validate & & Permit \\
\hline & Validate & & & \\
\hline & $\begin{array}{l}\text { Case } \\
\text { Status }\end{array}$ & Validate & & Permit \\
\hline & $\begin{array}{l}\text { Validate } \\
\text { Data COC }\end{array}$ & Validate & & Permit \\
\hline & $\begin{array}{l}\text { Download } \\
\text { Form COC }\end{array}$ & Download & & Permit \\
\hline \multirow[t]{2}{*}{ Subject } & Resource & Actions & Environment & Output \\
\hline & $\begin{array}{l}\text { Change } \\
\text { Code } \\
\text { Signature }\end{array}$ & Change & & Permit \\
\hline Lawyer & $\begin{array}{l}\text { Download } \\
\text { Form COC }\end{array}$ & Download & $\begin{array}{l}\text { IP Address: } \\
\text { 192.168.0.106 } \\
\text { Mac Address: } \\
\text { d5:6d:7e:19:c2:9 } \\
\text { c } \\
\text { Time Access: } \\
\text { 09.00-15.00 }\end{array}$ & Permit \\
\hline
\end{tabular}

Tabel 3 menjelaskan bahwa hasil pengujian access control LPBD meliputi semua komponen yang digunakan sebagai attribute dalam rancangan XACML policy berupa attribute subject, resource, actions, dan environment menghasilkan output pengujian sebanyak 15 permit yang artinya semua attribute yang digunakan dapat berjalan dengan baik dan berfungsi sebagaimana mestinya.

Pada bagian ini juga akan dijelaskan bahwa model access control yang paling memungkinkan digunakan pada LPBD yaitu ABAC karena dengan pertimbangan bahwa pendekatan menggunakan ABAC lebih fleksibel. Sebagaimana yang disebutkan oleh [17] bahwa ABAC akan lebih banyak digunakan dalam hal fleksibilitas dalam penerapat attribute terhadap user, dalam penelitian lain yang dikukan oleh [18] juga menyebutkan bahwa ABAC memiliki sejumlah feature yang lebih baik dari model pada generasi sebelumnya, salah satu diantara feature tersebut adalah bahwa ABAC memungkinkan pemberian grant access control melalui kombinasi dari sejumlah attribute elemen autorisasasi seperti: subject, resource, actions, dan environment menjadi satu keputusan access control.

Berdasarkan permasalahan yang terdapat pada latar belakang penelitian ini, bahwa terdapat permasalahan pada access control LPBD sebelumnya, yang dibuat hanya dengan mekanisme authentikasi dan otorisasi user saja yaitu metode authentikasi dan otorisasi username dan password, tidak adanya parameter lain yang mendukung proses otentifikasi dan otorisasi yang lebih kompleks. Model attribute based access control (ABAC) yang usulkan pada LPBD saat ini, merupakan sebuah solusi model akses kontrol yang lebih baik dan lebih tepat untuk model sistem seperti LPBD, dikarenakan ABAC merupakan model akses kontrol yang lebih fleksibel dalam penerapan atribut terhadap user, object, dan kondisi lingkungan [17] Hal ini telah sesuai dengan apa yang dikerjakan saat ini, bahwa model attribute based access control (ABAC) yang rancang khusus untuk LPBD telah menerapkan aturan policy berupa attribute subject, resource, action dan environment. Hal ini karena sebuah request akses tidak hanya memenuhi otentifikasi user saja, akan tetapi wajib memenuhi rule policy yang telah diberikan sebagai otorisasi terhadap object yang ada. Dengan adanya rancangan ABAC pada LPBD ini juga dapat meningkatkan tingkat keamanan sistem LPBD yang berisi bukti digital yang harus tetap terjaga keasliannya.

\section{PENUTUP}

Berdasarkan penjelasan rancangan konsep model attribute based access control (ABAC) pada lemari penyimpanan bukti digital (LPBD) yang telah dijelaskan sebelumnya maka dapat disimpulkan bahwa perancangan $\mathrm{ABAC}$ pada LPBD ini diawali dengan melakukan perancangan model ABAC LPBD, dilanjutkan dengan membuat konsep XACML policy dalam bentuk policy statement untuk dapat menyesuaikan antara kebutuhan ABAC dan kebutuhan LPBD, serta diimplementasikan dalam bentuk halaman login. Dengan hasil pengujian access control yang berjalan dengan baik dan berfungsi sebagaimana mestinya. 
Selain itu pendekatan menggunakan metode ABAC ini telah mampu menjadi solusi atas permasalahan access control LPBD sebelumnya. Metode ini juga dapat menjadi solusi dalam meningkatkan tingkat keamanan sistem LPBD yang dimana berisi bukti digital yang harus tetap terjaga keasliannya. Penelitian selanjutnya dapat memperbaiki akses kontrol yang kini belum dapat dilengkapi dengan uji coba schema rancangan XACML. Untuk itu perlu dilakukan penelitian berkaitan dengan schema struktur XACML yang ada. Selain melakukan pengujian schema struktur XACML perlu juga melakukan validasi terhadap rancangan XACML yang telah dibuat.

\section{DAFTAR PUSTAKA}

[1] Y. Prayudi, "Problema dan Solusi Digatal Chain of Custody Yudi Prayudi Abstract," Semin. Nas. Sains dan Teknol. Informas, no. 2011, 2014.

[2] Y. Prayudi and T. K. Priyambodo, "Secure and Trusted Environment as a Strategy to Maintain the Integrity and Authenticity of Digital Evidence," pp. 299-314, 2015.

[3] R. Ruuhwan, I. Riadi, and Y. Prayudi, "Evaluation of Integrated Digital Forensics Investigation Framework for the Investigation of Smartphones Using Soft System Methodology," Int. J. Electr. Comput. Eng., vol. 7, no. 5, p. 2806, 2017.

[4] I. Riadi, Sunardi;, and A. Firdonsyah, "Forensic Investigation Technique on Android's Blackberry Messenger using NIST Framework," Int. J. CyberSecurity Digit. Forensics, vol. 16, no. 4, pp. 198-205, 2017.

[5] Y. Prayudi and A. Ashari, "Digital Evidence Cabinets: A Proposed Framework for Handling Digital Chain of Custody," no. 9, pp. 30-36, 2014.

[6] K. Widatama, "Konsep Lemari Penyimpanan Bukti Digital Menggunakan Struktur Bahasa XML," Semin. Nas. Inform. dan Apl. ke-3 dengan tema "Digital Evid. Comput. Crime," p. 23, 2017.

[7] Y. A. Younis, K. Kifayat, M. Merabti, and Dummy, "An access control model for cloud computing environments," Proc.-2nd Int. Conf. Adv. Comput. Netw.
Secur. ADCONS 2013, vol. 19, no. 1, pp. 226-231, 2013.

[8] W. Stallings and L. Brown, Computer Security: Principles and Practice, 3rd Editio. USA: Pearson Education International, 2015.

[9] Y. Prayudi, A. Ashari, and T. K. Priyambodo, "Digital Evidence Cabinets: A Proposed Frameworks for Handling Digital Chain of Custody," Int. J. Comput. Appl., vol. 109, no. 9, pp. 30-36, 2014.

[10] N. Widiyasono, I. Riadi, and A. Luthfi, "Investigation on the services of private cloud computing by using ADAM Method," Int. J. Electr. Comput. Eng., vol. 6, no. 5, pp. 2387-2395, 2016.

[11] A. Kurniawan, I. Riadi, and A. Luthfi, "Forensic analysis and prevent of cross site scripting in single victim attack using open web application security project (OWASP) framework," J. Theor. Appl. Inf. Technol., vol. 95, no. 6, pp. 1363-1371, 2017.

[12] T. Priebe, W. Dobmeier, C. Schläger, and N. Kamprath, "Supporting attributebased access control in authorization and authentication infrastructures with ontologies," J. Softw., vol. 2, no. 1, pp. 27-38, 2007.

[13] R. Sandhu, "Security Models: Past , Present and Future," no. August. Institute for Cyber Security, UTSA USA, San Antonio, TX, USA, pp. 1-28, 2010.

[14] N. Dan and C. Yuan, "Attribute Based Access Control (ABAC) -based crossdomain access control in serviceoriented architecture (SOA)," pp. 14051408, 2012.

[15] X. Son Ha, T. Luong Khiem, and T. K. Dang, "Rew - XAC: An approach to rewriting request for elastic $\mathrm{ABAC}$ enforcement with dynamic policies," Int. Conf. Advenced Comput. Appl., pp. 2531, 2016.

[16] A. A. Abd El-Aziz and A. Kannan, "A comprehensive presentation to XACML," Third Int. Conf. Comput. Intell. Inf. Technol. (CIIT 2013), pp. 155-161, 2013.

[17] V. C. Hu et al., "Guide to attribute based access control (abac) definition and considerations," NIST Spec. Publ., vol. 800, p. 162,2014 